\title{
The private value of public pensions
}

\author{
Konstantin Petrichev \\ School of Finance and Economics, University of Technology, Sydney \\ Susan Thorp * \\ School of Finance and Economics, University of Technology, Sydney
}

\begin{abstract}
As individual retirement savings accounts replace public pensions and defined benefit schemes, more retirees will decumulate using commercial income streams rather than public or corporate annuities. Here we use an approximation to the retirement income problem (Huang, Milevsky and Yang 2004) to compute the cost of replicating a public real life annuity (the Australian Age Pension) using commercial decumulation products. We treat the public pension as a phased withdrawal plan, matching insurance and payment features, and back out the stochastic present value of the plan under an arbitrarily small ruin probability. To reproduce the pension payment with $99 \%$ certainty, a male retiree needs 3.6 times the current average retirement savings account balance, and a female retiree needs more than 10 times the average female account balance. At $95 \%$ certainty, required wealth falls by around $25 \%$. We measure separately the impact of gender, investment strategy, retirement age and management fees on this valuation.
\end{abstract}

JEL codes: H55; J14; G11 Subject category: IE25 Insurance branch: IB80; IB81. Key words: Social security; Longevity risk; Phased withdrawal; Stochastic present value 


\section{Introduction}

Governments across the world are reviewing pension systems in the light of increasing public liabilities, and reassessing the basic redistributive pensions that comprise the 'first pillar' of retirement savings systems. Basic pensions ensure that the elderly reach a minimum level of welfare, and are typically payments of between $20 \%$ and $40 \%$ of average earnings, targeted towards the needy via income and assets testing (Whitehouse 2007).

New policies aim to reduce dependence on public funds by encouraging saving into individual accounts. In addition, more corporate pension providers are directing members towards defined contribution (DC) rather than defined benefit (DB) schemes. One implication of replacing public pensions (or DB schemes) with individual accounts is that personal savers often need to decumulate using commercially-provided income streams such as phased withdrawals or annuities. It follows that one valuation of a public pension is the cost of reproducing it using these alternative products, in the event that no

$\bar{*}$ Corresponding address: School of Finance and Economics, PO Box 123, Broadway NSW 2007, Australia. Tel: +61 29514 7784; Fax: +61 295147722.

Email address: susan.thorp@uts.edu.au (Susan Thorp).

0 Thanks to Geoff Kingston, Moshe Milevsky, an anonymous reviewer, participants at the 15th Australian Colloquium of Superannuation Researchers, Sydney and the 11th Asia-Pacific Risk and Insurance Association Conference, Taipei, for helpful comments. Thorp acknowledges support from the Australian Research Council ARC DP0877219. 
exactly replicating product or strategy exists.

Here we apply new analytical tools from ruin theory to estimate the wealth that a self-funded retiree needs to generate privately an income stream that is equivalent to a public pension, matching real value and insurance protection. We use an approximation to the retirement income problem developed by Huang et al. (2004) and Milevsky and Robinson (2000, 2005). We calculate the purchase price and money's worth ${ }^{1}$ of income streams offered in private financial markets that closely replicate the Australian basic pension. While this analysis focuses on the cost of replacing a public real annuity with a private phased withdrawal, the techniques we apply are general and could be used to compare many types of decumulation plans.

For an infinite horizon and lognormally distributed investment returns, the stochastic present value of a desired spending plan is reciprocal gamma distributed. In the more general case, when time horizons are finite and stochastic, the approximate probability of running out of resources before the end of life can be computed using moment matching arguments. By fixing the probability of ruin at an arbitrarily low level to approximate the small regulatory risk of the public pension, we can back out the minimum wealth needed to replace a pension using available commercial phased withdrawals and annuities. In addition, we compute the money's worth of the best phased withdrawal strategies by calculating the ratio of the simple annuity value of the public pension stream to the total retirement wealth needed for self-insurance.

The most efficient pension-matching investment strategy is either a 'Balanced'

$\overline{1}$ The money's worth is the ratio of the expected present value of an annuity stream to its purchase price. 
or 'Growth' portfolio with around 50-70\% allocated to equities and property securities, but this may vary by age, gender and risk tolerance. The money's worth ratios of the best strategies are generally below 0.5 , they decline as the retiree ages, and are lower for men than for women. In terms of accumulation, the retiree needs close to $\$ 380,000$ at age 65 to ensure the life-long $\$ 14,000$ p.a. real income now paid by the Australian basic pension. This is more than four times the average retirement savings account balance of current retirees. Delaying retirement to age 70 decreases the required accumulation by around $\$ 25,000$, while ensuring that the payment stream maintains parity with earnings growth as well as inflation increases it by around $\$ 90,000$. In addition, for each $1 \%$ increase in management fees or administrative loadings, required wealth rises by around $\$ 60,000$. Significantly less is needed if the retiree pools longevity risk by purchasing commercial life annuities, but voluntary annuitization is very rare among Australian retirees, and no commercial product perfectly matches the basic pension.

Section 2 sets out the main features of the Australian pension system. We describe the method for calculating the stochastic present value of a spending plan in Section 3, and Section 4 outlines parameter choices. In Section 5 we compute the wealth required by men and women of retirement age to construct a secure pension payment via self-annuitization plans and compare these plans across a range of key features. Section 6 concludes. 


\section{The pension system}

Unlike most developed countries, Australia does not have a public, earningslinked pension system. ${ }^{2}$ This feature, along with the fact that the majority of Australian retirees rely on both public first-pillar and private second-pillar provisions for retirement income, create a natural experiment in the interaction between targeted government retirement support and mandatory savings into individual accounts.

Recent survey data show that $70-80 \%$ of Australian households over the age of 64 depend on the basic Age Pension (or the war veteran's equivalent) as their primary source of income (ABS 2006), and as the population ages in the next four decades, fiscal funding requirements are expected to increase (Commonwealth of Australia 2007). Since 1992, Australian workers have contributed a mandatory $9 \%$ of income to privately-managed and fully-funded personal retirement savings accounts, but accumulations are still relatively modest, currently averaging less than $\$ 100,000$ at retirement (ASFA 2007) and projected to be less than $\$ 150,000$ by $2020{ }^{3}$ As a result, most retirees will continue to depend on first-pillar income support in coming decades.

The current Age Pension for a single home-owner is $\$ 525$ per fortnight, or $\$ 13,653$ p.a. (US $\$ 11,880)$. Pensioners also receive allowances worth more than $\$ 340$ p.a. to cover necessary expenses such as utilities and pharmaceuticals. In the analysis below we study the case of a single home-owning pensioner whose

$\overline{2}$ For a complete discussion of the US system see McGill et al. (2005), and for the UK, see Department for Work and Pensions (2006a, 2006b).

3 Kelly et al. (2002) projects an average balance of $\$ 119709$ by 2020 in 1999 dollars, which we scale up by $20 \%$ to get an estimate in 2007 dollars. 
annual benefit is rounded to $\$ 14,000$ to encompass the basic payment and the most common allowances.

The base single pension is recalculated every six months to keep up with changes in the Consumer Price Index (CPI) and also to ensure that it does not fall below 25\% of Male Total Average Weekly Earnings (MTAWE). Pensioners thus hold an option on the general level of wages and prices so that the relative as well as real value of payments is maintained. The adjustment in the base pension is

$$
\frac{P_{t}}{P_{t-1}}=\max \left[\left(1+h_{t}\right),\left(1+n_{t}\right)\right]
$$

where $h_{t}$ is the rate of increase in the CPI and $n_{t}$ is the rate of increase in MTAWE over the previous six months. Earnings growth has exceeded inflation for most of the past 15 years. Figure 1 below graphs annualized 6-monthly paths for inflation and MTAWE, since March 1989.

\section{[INSERT FIGURE 1 HERE]}

The average annualized increase in the CPI over this period was $3.1 \%$ compared with $4.5 \%$ for MTAWE and $4.9 \%$ for the maximum of both the CPI and MTAWE.

Means-testing of the Age Pension creates other option-like features over the wealth of the retired. The means tests begin to reduce the pension at fixed levels of income and/or wealth, tapering to zero as income and/or wealth increases and encouraging higher rates of consumption early in retirement. ${ }^{4}$ An

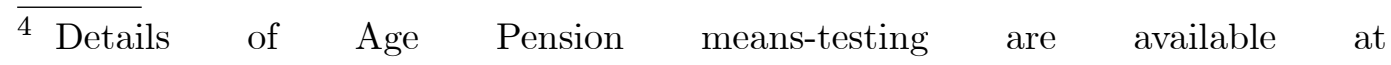
http://www.centrelink.gov.au/. For the remaining analysis we do not study the pension taper since the majority of retirees receive the full pension. 
optimizing retiree will trade off the marginal advantages of pension eligibility against the costs of lower wealth/income. On the other hand, means-testing ensures that retirees with enough personal savings will become ineligible for government provision, and will rely on private-sector provision of decumulation services.

Since no commercial product replicating the Age Pension is available, ineligibility can expose self-funded retirees to investment and longevity risk. Even though life annuities fairly similar to the Age Pension are sold, voluntary purchase of longevity insurance is unpopular in Australia, as in many developed countries (James and Song 2001). The majority of Australian retirees take their second pillar payouts as discretionary lump-sums or as phased withdrawal plans. Data on the allocation of Australian retirement savings are sparse, but survey evidence suggests that $12 \%$ of retirement savings are used to purchase income stream products (ABS 2006), and of that, less that $0.2 \%$ go to life annuities (Plan for Life 2006).

In the next section we outline a method for calculating the stochastic present value of a pension-equivalent income stream from a phased withdrawal product.

\section{Stochastic present value of retirement wealth}

To compare the public pension with phased withdrawals (which have investment and longevity risk), we need a method that accounts for the likelihood 
of failure or ruin under a self-annuitization scheme. ${ }^{5}$

Consider a portfolio of risky assets following a geometric Brownian motion with known drift and diffusion,

$$
\begin{aligned}
d S_{t} & =\mu S_{t} d t+\sigma S_{t} d B_{t} \\
S_{t} & =e^{\left(\mu-1 / 2 \sigma^{2}\right) t+\sigma B_{t}}, S_{0}=1 .
\end{aligned}
$$

where $B_{t}$ is a standard Wiener process. The retiree consumes at a continuous rate of one dollar per year, so the wealth process is

$$
d W_{t}=d S_{t}-1 d t=\left(\mu W_{t}-1\right) d t+\sigma W_{t} d B_{t}, W_{0}=w
$$

with solution

$$
W_{t}=S_{t}\left[w-\int_{0}^{t} S_{t}^{-1} d t\right], W_{0}=w
$$

The draw-down process (5) can become negative if the drift $\mu W_{t}$ is small, precipitating ruin.

We evaluate retirement consumption plans by determining the probability of exhausting wealth before the end of life:

$$
\phi(w) \equiv \operatorname{Pr}\left[\inf _{0 \leq s \leq T} W_{s} \leq 0 \mid W_{0}=w\right]
$$

or the likelihood that the lowest value of the stochastic process (5) goes to zero before the retiree reaches the end of life at terminal date, $T$.

Since the portfolio return $S_{t}$ is bounded away from zero, retirement wealth can go to zero only if the stochastic present value of the spending plan approaches initial wealth. Therefore the probability of ruin before a pre-determined time $T$ is

$\overline{5}$ In this section we follow Milevsky (2006, chapter 9 and appendix to chapter 9) and Huang et. al (2004). 


$$
\begin{aligned}
\phi(w) & =\operatorname{Pr}\left[w \leq \int_{0}^{T} e^{-\left(\mu-1 / 2 \sigma^{2}\right) t-\sigma B_{t}} d t\right]=1-\operatorname{Pr}\left[Z_{T}<w\right] \\
Z_{T} & \equiv \int_{0}^{T} e^{-\left(\mu-1 / 2 \sigma^{2}\right) t-\sigma B_{t}} d t .
\end{aligned}
$$

If the time horizon is infinite, Huang et al. (2004) prove that the ruin probability has a closed form analytic solution.

Here we look at the case of an uncertain and finite length of life, where $T_{x}<\infty$ is a random variable following a known mortality law, but where the density of the random variable $Z_{T_{x}} \equiv \int_{0}^{T_{x}} e^{-\left(\mu-1 / 2 \sigma^{2}\right) t-\sigma B_{t}} d t$ is unknown, and where the probability of ruin is $\phi(w)=1-\operatorname{Pr}\left[Z_{T_{x}}<w\right]$.

The first moment of the distribution of $Z_{T_{x}}$ is

$$
E\left(Z_{T_{x}}\right)=\int_{0}^{\infty} e^{-\left(\mu-\sigma^{2}\right) t}{ }_{t} p_{x} d t
$$

where ${ }_{t} p_{x}$ is the probability of surviving to age $t+x$ conditional on having survived to age $x$. Under a Gompertz law for mortality, (9) evaluates to

$$
\begin{aligned}
M^{(1)} & =E\left[Z_{T_{x}}\right]=A(\xi \mid m, b, x) \\
\xi & \equiv\left(\mu-\sigma^{2}\right) \\
A(\xi \mid m, b, x) & \equiv b \exp \left\{\exp \left[\frac{x-m}{b}\right]+(x-m) \xi\right\} \Gamma\left(-b \xi, \exp \left[\frac{x-m}{b}\right]\right)
\end{aligned}
$$

where $\Gamma(u, v)=\int_{v}^{\infty} e^{-t} t^{(u-1)} d t$ is the incomplete Gamma function, and $b$ and $m$ are the scale and mode parameters of the Gompertz function. Similarly, the second moment is

$$
M^{(2)}=E\left[Z_{T_{x}}^{2}\right]=\left(\frac{2}{\mu-2 \sigma^{2}}\right)\left[A\left(\mu-\sigma^{2} \mid m, b, x\right)-A\left(2 \mu-3 \sigma^{2} \mid m, b, x\right)\right] .
$$

Having identified the first two moments of the true but unknown density function of $Z_{T_{x}}$, the issue is to what known density function can they be 
approximated so that ruin probabilities can be evaluated analytically? The limiting distribution for $Z_{\infty}(T \rightarrow \infty)$ is a reciprocal Gamma distribution,

$$
\operatorname{Pr}[Z<z] \equiv \frac{\beta^{-\alpha}}{\Gamma(\alpha)} \int_{0}^{t} y^{-(\alpha+1)} e^{(-1 / y \beta)} d y
$$

which has first and second moments of

$$
M^{(1)}=\frac{1}{\beta(\alpha-1)}, \quad M^{(2)}=\frac{1}{\beta^{2}(\alpha-1)(\alpha-2)}
$$

so that

$$
\alpha=\frac{2 M^{(2)}-M^{(1)} M^{(1)}}{M^{(2)}-M^{(1)} M^{(1)}}, \quad \beta=\frac{M^{(2)}-M^{(1)} M^{(1)}}{M^{(2)} M^{(1)}} .
$$

Given this limiting result, Huang et al. (2004) propose approximating the distribution of $Z_{T_{x}}$ by using the moments derived above in equations (10) (11), substituting into (14), and numerically evaluating $\phi(w)=1-\operatorname{Pr}\left[Z_{T_{x}}<\right.$ $w]=\operatorname{Pr}\left[Z_{T_{x}}>w\right]$ as a reciprocal Gamma random variable.

The probability that a reciprocal Gamma random variable is greater than a particular value is equal to the probability that a Gamma random variable is less than the inverse of that value, or,

$$
\phi(w)=\operatorname{Pr}\left[\inf _{0 \leq s \leq T} W_{s} \leq 0 \mid W_{0}=w\right] \cong \mathbf{G}\left(\frac{1}{w} \mid \alpha, \beta\right)
$$

where the right hand side is the probability that a random variable with a Gamma distribution defined by $\alpha$ and $\beta$ is less than $\frac{1}{w}$. (Because one of the parameters of the Gamma distribution is negative in our numerical problems, we rescale using the method described in Appendix A.)

A basic pension is like a very safe phased withdrawal plan - one where the likelihood of ruin is the small, but non-zero, risk that regulators will remove or reduce the pension payment. If we estimate the inflation and earnings-adjusted drift and diffusion of a phased withdrawal, and incorporate the mortality of 
a typical retiree, we can fix the probability of ruin under the plan at some arbitrarily small number, say, $1 \%$, and infer the size of required initial wealth $W_{0}=w$ using (15). This required wealth $W_{0}=w \mid \phi(w)=0.01$ is the stochastic present value of a phased withdrawal (investment and draw-down strategy) that substantially replicates the Age Pension.

\section{Parameter selection}

Reproducing the Age Pension payment stream using the stochastic present value method requires four parameters - the drift and diffusion terms for the portfolio process $\mu$ and $\sigma$, that is the return and volatility of the portfolio selected by the retiree, and the survival probability, a function of the Gompertz scale and mode parameters $b$ and $m$.

\subsection{Portfolio return and volatility}

Our retiree can select from five investment strategies, labelled High Growth, Growth, Balanced, Conservative and Capital Stable. Each is a combination of two or more asset classes from Australian shares, international shares, Australian property securities, Australian fixed interest and cash. Portfolio weights are typical of commercial phased withdrawal products but not necessarily optimal (Table 1). The portfolios decline in exposure to growth assets, from $90 \%$ allocation to shares and property in the High Growth fund, 70\% in Growth, $50 \%$ in Balanced, $30 \%$ in the Conservative fund and Capital Stable entirely invested in cash and fixed-interest securities.

[INSERT TABLE 1 HERE] 
We collect monthly time series of returns indices for each asset class over the 16-year period, 30 December 1989 - 30 June 2006, and compute a monthly periodic return using weights from Table 1. Nominal portfolio returns are $\left(1+i_{P, t}\right)=\sum_{j=1}^{n} \omega_{j}\left(1+i_{j, t}\right)$ where $\left(1+i_{P, t}\right)$ is the gross nominal monthly portfolio return over month $t, \omega_{j}$ is the proportion allocated to asset class $j$ and $\left(1+i_{j, t}\right)$ is the nominal monthly gross return to asset index $j$. To translate this to a real return, we derive a monthly percentage change in the quarterly CPI by linear interpolation $h_{t}$ (or for MTAWE, $n_{t}$ ) and compute the monthly log-change in the real portfolio return as

$$
r_{P, t}=\ln S_{t}-\ln S_{t-1}=\ln \left(1+i_{P, t}\right)-\ln \left(1+h_{t}\right)
$$

or if we deflate by the greater of inflation and earnings growth

$$
r_{P, t}=\ln S_{t}-\ln S_{t-1}=\ln \left(1+i_{P, t}\right)-\ln \left(\max \left[\left(1+h_{t}\right),\left(1+n_{t}\right)\right]\right) .
$$

The annualized expected value $\mu$ and volatility $\sigma$ of this process are:

$$
\begin{aligned}
\mu & =12 \frac{1}{T} \sum_{t=1}^{T}\left(r_{P, t}\right)+\frac{1}{2} \sigma^{2}, \quad \sigma=s \sqrt{12}, \\
s & =\sqrt{\frac{1}{T-1} \sum_{t=1}^{T}\left(r_{P, t}\right)^{2}-\frac{1}{T(T-1)}\left[\sum_{t=1}^{T}\left(r_{P, t}\right)\right]^{2}},
\end{aligned}
$$

where $T$ is the number of observations.

Table 2 shows the nominal and real returns and volatilities for each of the portfolios. The average inflation rate is $2.8 \%$ and the average earnings-augmented deflation is $4.4 \%$. The relatively low volatility of growth portfolios is partly due to low volatility in Australian equity returns over this sample period (around $12.5 \%$ annualized). We also deduct an indicative management fee from the real returns, such as are charged by providers of phased withdrawal products offer- 
ing similar investments (see, for example, AMP (2007) for accounts of value 100-499K). Jarque-Bera tests of the monthly real log portfolio returns fail to reject the hypothesis of normality at the $5 \%$ level for all portfolios except the High Growth portfolio where the null is accepted at the $1 \%$ level.

[INSERT TABLE 2 HERE]

\subsection{Gompertz force of mortality}

Given an instantaneous force of mortality $\lambda(t)$, the conditional probability of survival under the Gompertz law, ${ }_{t} p_{x}$, can be expressed as

$$
\begin{aligned}
{ }_{t} p_{x} & =\exp \left[-\int_{x}^{x+t} \lambda(s) d s\right] \\
& =\exp \left[b \lambda_{x}\left(1-e^{\frac{t}{b}}\right)\right],
\end{aligned}
$$

where

$$
\lambda(x)=\frac{1}{b} \exp \left(\frac{x-m}{b}\right) .
$$

Parameters $b$ and $m$ are estimated using non-linear least squares as $\log \left(p_{x}\right)=$

$\exp \left(\frac{x-m}{b}\right)\left(1-\exp \frac{1}{b}\right)$, taking discrete mortality data, $p_{x}$, from the Australian Life Tables 2000-2002 (Commonwealth of Australia 2004). The conditional survival probability $p_{x}$ used in estimation is adjusted by 25 year improvement factors as described in the Life Tables. Model fit worsens if the sample includes the thin mortality data at extreme old age, so the sample runs from ages 50 to 90 . Table 3 reports estimation results for males and females. ${ }^{6}$

$\overline{6}$ The mortality model here we treat as being known with certainty. We do not account for inaccuracies in the projections of mortality, parameter risk or model risk in our measures of stochastic present value. For a discussion of the extensive 
[INSERT TABLE 3 HERE]

\section{$5 \quad$ Valuing the basic pension}

The most obvious way to value the basic pension is as a standard annuity. We begin with this computation and then use moment matching to approximate the stochastic present value of equivalent phased withdrawal plans. Finally we compute the money's worth of the best phased withdrawals and test the effects of delaying retirement and of varying management fees.

\subsection{Annuity value of the Age Pension}

The Age Pension payment is an indexed immediate life annuity. We compute $V_{x}(A)$, the expected discounted value of the annuity,

$$
V_{x}(A)=\sum_{t=1}^{T-x}{ }_{t} \bar{p}_{x} \frac{A}{(1+\bar{r})^{t}}
$$

where $A$ is the pension payment, here assumed to be $\$ 14,000$ p.a., $\bar{r}$ is the real rate of interest on long duration government debt, ${ }_{t} \bar{p}_{x}$ is the (discrete) probability that an individual of age $x$ survives another $t$ years, and $T$ is the oldest old age in the Life Tables. Consistent with the return estimates set

out in Section 4, we assume a flat term structure, and set $\bar{r}$ as the geometric mean of the annualized monthly yield on a 5 year Treasury Bond (Reserve Bank of Australia series) divided by either the geometric mean inflation or the geometric mean of the maximum of the increase in the CPI or MTAWE, for December 1989 - June 2006. We compute ${ }_{t} \bar{p}_{x}$ using the improved probabilities literature on dynamic mortality modelling see Pitacco (2004) and references therein. 
for males/females from the 2002 Australian Life Tables. Table 4 sets out these annuity values by gender and age.

[INSERT TABLE 4 HERE]

\subsection{Risk of ruin}

Table 5 shows the probability that an individual with a fixed consumption plan will run out of money before the end of life. In this example our investor reaches age 65 and retires with a net $\$ 1,000,000$ and then decides on a fixed real spending plan of between $\$ 40,000$ and $\$ 100,000$ each year. The lowest retirement ruin probability for each draw-down rate is marked with an asterisk. For $4-6 \%$ of initial retirement wealth, the Growth portfolio is least likely to be exhausted, whereas at higher expenditure ( $8 \%$ of initial wealth) the High Growth portfolio is safer.

\section{[INSERT TABLE 5 HERE]}

If preferences are measurable in terms of ruin probability, then a retiree might use this table to decide on an investment and spending plan by trading off an increase in ruin probability against an increase in spending. However, maintaining a constant real level of consumption is not an optimal strategy under most conventional utility functions. As Brown (2000) points out, a constant level of consumption (manifesting in complete unwillingness to transfer consumption across time) implies infinite risk aversion for an individual with constant relative risk aversion (CRRA) preferences. And further, the utility maximizing consumer with CRRA preferences will never allow wealth to fall to zero because the marginal utility of consumption is infinite at zero. Bayraktar 
and Young (2007) also show that ruin minimization and utility maximization will be synonymous when consumption plans are linear in wealth (as for Hyperbolic Absolute Risk Aversion preferences) rather than when consumption is fixed at a some level.

\subsection{Wealth value of the basic pension}

Table 6 sets out the initial wealth needed to support a pension-equivalent payment for men and women of average improved mortality investing in managed funds, and at ruin probabilities between 1, 3 and 5\%. We compute this wealth amount for age 65, noting that the average second-pillar retirement accumulation of $60-65$ year old Australians is around $\$ 44,000$ for females and $\$ 130,000$ for males (ASFA 2007).

\section{[INSERT TABLE 6 HERE]}

The lowest retirement wealth for a 65 year-old female at a $1 \%$ ruin probability is $\$ 379,000$, invested in the Balanced portfolio. This amount is 8.6 times current average retirement savings balances for this age group of women. By contrast, commercial insurance firms offer CPI-indexed single life annuities paying $\$ 14,000$ p.a. at a premium of $\$ 338,000$ (DeXX\&R 2007). Allowing for $5 \%$ ruin lowers the required accumulation to $\$ 296,000$.

For males, wealth requirements are similar to females at the $1 \%$ probability of ruin. The slightly riskier growth portfolios, with $70 \%$ exposure to equity and property assets are most efficient for generating the real income stream. A 65

year old male needs $\$ 379,000$, a sum about three times as large as estimates of the current average male accumulation. A single-life, CPI-indexed annuity for 
a 65 year old male costs $\$ 329,000$, which, again, is less costly than the phased withdrawals (DeXX\&R 2007).

Table 7 shows the wealth needed at retirement to generate a pension-equivalent income stream that maintains both real value and parity with earnings.

\section{[INSERT TABLE 7 HERE]}

At our benchmark $1 \%$ probability of ruin, a 65 year old female needs $\$ 477,000$ in retirement savings to generate the earnings- and inflation-adjusted pension payment. This is $26 \%$ more than required wealth in Table 6 , suggesting that the value of linking the pension to MTAWE is substantial. Males require $\$ 470,000$, a $24 \%$ increase over the amount needed to match only inflation increases. The closest commercial single life annuity to the earnings-linked Age Pension payment is a single life indexed to rise at $5 \%$ p.a. A 65 year old female would pay $\$ 422,000$ for a $5 \%$ indexed annuity paying $\$ 14,000$ in the first year, whereas the premium for a male is currently $\$ 368,000$, again, below the cost of self-insurance via phased withdrawals (DeXX\&R 2007).

\subsection{Money's worth}

If we choose the least-cost investment strategy and allow the time of retirement to vary, we can compare the money's worth of pension-equivalent phased withdrawal plans over a range of ages. The money's worth is the ratio of the expected net present value of the annuity stream to its purchase price (Mitchell et al. 1999), or in our case, the ratio of the expected net present value of the pension payment (Table 4) to required initial wealth of the phased withdrawals (Tables 6 and 7). 
Studies of the money's worth of immediate nominal single life annuities across a range of countries find that commercial offerings represent reasonable value for consumers (James and Song 2001). For the US and Australia, Mitchell and McCarthy (2004) and Doyle et al. (2004) report money's worth ratios above 0.8 and 0.9 respectively. Similarly, Cannon and Tonks (2004) put the money's worth of UK annuities above 0.9 .

In Figure 2 below, we graph the money's worth of the least-cost phased withdrawal as the age and gender of the pensioner varies. For women this is either the Balanced or Growth portfolio, and for men, the Growth portfolio.

\section{[INSERT FIGURE 2 HERE]}

The money's worth of the phased withdrawal strategy decreases with increasing age, and is higher for females than for males. Most phased withdrawals offer a money's worth ratio below 0.5 . The highest ratio is 0.52 for a 65 year old female matching an inflation-indexed payment, and the lowest is 0.29 for an 80-year-old male matching a CPI-MTAWE indexed payment. By comparison, the money's worth of the commercial immediate life annuities for CPI/CPIMTAWE indexing are 0.54/0.57 for males, and 0.59/0.56 for females at age 65.

Management fees are a major component of the cost of these self-insurance strategies. Figure 3 graphs the impact of varying management fees from $0-2 \%$ p.a. in the best phased withdrawal strategy for males and females aged 65 years. The money's worth of each strategy declines linearly as fees increase: the ratio for females falls by 0.15 as fees increase from $0-2 \%$, and the ratio for males falls less steeply by 0.12 . The impact on wealth required at retirement is substantial. For the CPI-MTAWE-indexed plans the difference in wealth 
between zero and $2 \%$ fees for females is $\$ 126,867$ and for males is $\$ 112,048$. In other words, for each $1 \%$ increase in fees, a retiree needs an additional $\$ 60,000$ in wealth.

\section{[INSERT FIGURE 3 HERE]}

\section{Conclusion}

One method for valuing a retirement income stream, including a public pension, is to calculate what it might cost to reproduce using alternative products. Since the exact density function of the stochastic present value of any retirement spending plan is not known when lifetimes are uncertain, here we use a moment-matching approximation of Milevsky and Robinson (2000, 2005) and Huang et al. (2004) to compare decumulation plans. We allow for a very low probability of reaching 'ruin' as a way of accounting for regulatory risk, and back out the initial nest egg needed to replicate the payment and insurance features of a simple real life annuity (the Australian basic pension) using phased withdrawal products. This method gives a valuation of a basic pension in terms of the cost of a similar self-insured draw-down plan.

We estimate the value of the Australian basic pension (the Age Pension) is in the order of $\$ 450,000$ at age 65 if the probability of ruin is $1 \%$. This amount is many times larger than current average personal retirement accumulations and represents a substantial implicit transfer of public funds at retirement. Required wealth is generally larger for women because of longer life expectancy, and harder for women to attain by private savings. Delaying retirement by five years reduces required wealth by $5 \%$ or less. On the other hand, $25 \%$ 
more wealth is needed to maintain the relativity of the pension with average earnings, as compared with consumer prices, and around $6 \%$ more wealth is needed for each $1 \%$ increase in investment management fees. The money's worth ratio of the phased withdrawal products surveyed here is generally less than 0.5. And despite their marked unpopularity with the retired, commercial life annuity products currently mimic public pension payment paths more cheaply than drawn-downs from managed funds.

\section{Appendix A: Rescaling the incomplete gamma function}

A numerical complication arises from the fact that the incomplete gamma function which appears in the moments (10) and (11) is difficult to compute because $-\xi b<0$ in our examples, and many software packages will not return gamma values defined over negative parameters. A rescaling derived from Milevsky (2001) allows the incomplete gamma function to be rewritten over $(-\xi b+\Delta)>0$ where $\Delta$ is a positive integer.

To evaluate the moments (10) and (11) we need values of the incomplete gamma function:

$$
\begin{aligned}
\Gamma(a, c) & =\int_{c}^{\infty} e^{-x} x^{(a-1)} d x \\
& =\Gamma(a)\left(1-G_{a}(c)\right) .
\end{aligned}
$$

where $a=-\xi b$ and $c=\exp \left[\frac{x-m}{b}\right]$. Milevsky (2001) suggests redefining the incomplete gamma function over, say, $a+1=-\xi b+1$.

Integrating (22) by parts gives

$$
\int e^{-x} x^{(a-1)} d x=e^{-x} \frac{1}{a} x^{a}+\frac{1}{a} \int e^{-x} x^{a} d x
$$


and so

$$
\Gamma(a, c)=-\frac{c^{a} e^{-c}}{a}+\frac{1}{a} \Gamma(a+1, c) .
$$

Using (25) we can rewrite $\Gamma(a, c)$ as:

$$
\Gamma(a, c)=\frac{1}{a} \Gamma(a+1)\left(1-G_{a+1}(c)\right)-\frac{c^{a} e^{-c}}{a} .
$$

Equation (26) is easily programmed into standard spreadsheet packages. When $-2<-\xi b<-1$, we rescale to $-\xi b+2$ using the recursion:

$$
\Gamma(a, c)=\frac{1}{a}\left[\frac{1}{a+1} \Gamma(a+2)\left(1-G_{a+2}(c)\right)-\frac{c^{a+1} e^{-c}}{a+1}\right]-\frac{c^{a} e^{-c}}{a} .
$$




\section{References}

AMP 2007. Allocated pension product disclosure statement. Sydney: AMP.

ASFA 2007. Pre-budget submission for 2007-2008 Federal Budget. Sydney: Association of Superannuation Funds of Australia.

ABS 2006. Retirement and retirement intentions, August 2004-June 2005. Canberra: Australian Bureau of Statistics.

Bayraktar, E., Young, V.R., 2007. Correspondence between lifetime minimum wealth and utility of consumption. Finance and Stochastics 11, 213-236.

Brown, J.R., 2000. Comment on 'Self-annuitization and ruin in retirement'. North American Actuarial Journal 4, 126-127.

Cannon, E., Tonks, I., 2004. UK annuity rates, money's worth and pension replacement ratios 1957-2002. Geneva Papers on Risk and Insurance 29, 371-393.

Commonwealth of Australia 2007. Intergenerational Report 2007, Canberra: Department of Treasury.

Commonwealth of Australia 2004. Australian Government Actuary's Australian Life Tables: 2000-02. Canberra: AGPS.

Department for Work and Pensions 2006a. Security in retirement: towards a new pension system. http://www.dwp.gov.uk/pensionsreform/

Department for Work and Pensions 2006b. Personal accounts: a new way to save. http://www.dwp.gov.uk/pensionsreform/

DeXX\&R 2007. Retirement incomes league tables: Quarterly statistics December 2006, Hurstville: RKR Research. 
Doyle, S., Mitchell, O., Piggott, J., 2004. Annuity values in defined contribution retirement systems: Australia and Singapore compared. Australian Economic Review 37, 402-416.

Huang, H., Milevsky, M.A., Wang, J., 2004. Ruined moments in your life: How good are the approximations? Insurance: Mathematics and Economics 34, 421-447.

James, E., Song, X., 2001. Annuities markets around the world: money's worth and risk intermediation. Working Paper. Washington: Pension Research Institute.

Kelly, S., Harding, A., Percival, R., 2002. Live long and prosper? Projecting the likely superannuation of the baby boomers in 2020. National Centre for Social and Economic Modelling, Canberra: University of Canberra.

McGill, D.M., Brown, K.N., Haley, J.J., Schieber, S.J., 2005. Fundamentals of Private Pensions, 5th Edn. Oxford: Oxford University Press.

Milevsky, M.A., 2006. The Calculus of Retirement Income. New York: Cambridge University Press.

Milevsky, M. A., 2001. Working with Gamma annuities, unpublished note, Toronto: York University.

Milevsky, M.A., Robinson, C., 2005. A sustainable spending rate without simulation. Financial Analysts Journal 64, 89-100.

Milevsky, M.A., Robinson, C., 2000. Self-annuitization and ruin in retirement. North American Actuarial Journal 4, 112-124.

Mitchell, O., McCarthy, D., 2004. Annuities for an ageing world. In: Fornero, E., Luciano, E., (Eds.). Developing an Annuities Market in Europe. Cheltenham: Edward Elgar, 19-68.

Mitchell, O., Poterba, J.M., Warshawsky, M.J., Brown, J.R., 1999. New evidence 
on the money's worth of individual annuities. American Economic Review 89, 12991318.

Pitacco, E., 2004. Survival models in a dynamic context: a survey. Insurance: Mathematics and Economics 35, 279-298.

Plan for Life 2006. The pension and annuity market research report. Melbourne: Plan For Life Research.

Whitehouse, E., 2007. Pensions Panorama. Washington: World Bank. 